\title{
Segmented intravaginal ring for the combination delivery of hydroxychloroquine and anti-CCR5 siRNA nanoparticles as a potential strategy for preventing HIV infection
}

\author{
Yannick L. Traore ${ }^{1,2} \cdot$ Yufei Chen ${ }^{1,3} \cdot$ Fernanda Padilla $^{3} \cdot$ Emmanuel A. Ho $^{1,2} \mathbb{D}$
}

Accepted: 6 April 2021 / Published online: 17 April 2021

(c) The Author(s) 2021, corrected publication 2021

\begin{abstract}
Vaginal drug delivery has been shown to be a promising strategy for the prevention of sexually transmitted infections. Therapy delivered at the site of infection has many advantages including improved therapeutic efficacy, reduction in systemic toxicity, and reduced potential for development of drug resistance. We developed a "smart" combination intravaginal ring (IVR) that will (1) provide continuous release of hydroxychloroquine (HCQ) to induce T cell immune quiescence as the first-line of defense and (2) release nanoparticles containing anti-CCR5 siRNA only during sexual intercourse when triggered by the presence of seminal fluid as the second-line of defense. The IVR was capable of releasing HCQ over 25 days with a mean daily release of $31.17 \pm 3.06 \mu \mathrm{g} / \mathrm{mL}$. In the presence of vaginal fluid simulant plus seminal fluid simulant, over $12 \times$ more nanoparticles $(5.12 \pm 0.9 \mathrm{mg})$ were released over a 4-h period in comparison to IVR segments that were incubated in the presence of vaginal fluid simulant alone $(0.42 \pm 0.19 \mathrm{mg})$. Anti-CCR5 siRNA nanoparticles were able to knockdown $83 \pm 5.1 \%$ of CCR5 gene expression in vitro in the $\mathrm{CD} 4^{+} \mathrm{T}$ cell line Sup-T1. The IVR system also demonstrated to be non-cytotoxic to VK2/E6E7 vaginal epithelial cells.
\end{abstract}

Keywords HIV · Intravaginal ring $\cdot \mathrm{pH}$-responsive polymer $\cdot$ Anti-CCR5 siRNA $\cdot$ Solid lipid nanoparticles

\section{Introduction}

Despite the efforts that have been made to date, HIV is still one of the leading causes of death in developing countries. More than 38 million people globally are living with HIV at the end of 2019 with women being more vulnerable due to biological and social-cultural factors. Reasons include the larger surface area of the female genital tract (FGT) in comparison to the male genital tract and the fact that after sexual intercourse, semen remains within the FGT for prolonged periods, increasing exposure to HIV [1-3]. Condoms remain as the best method for preventing HIV infection during heterosexual intercourse, but unfortunately, in certain

Emmanuel A. Ho

Emmanuel.ho@uwaterloo.ca

1 Laboratory for Drug Delivery and Biomaterials, School of Pharmacy, University of Waterloo, Kitchener, Canada

2 Waterloo Institute for Nanotechnology, Waterloo, Canada

3 College of Pharmacy, University of Manitoba, Winnipeg, Canada developing countries, women are not able to negotiate condom usage with their partners [4]. Furthermore, due to the high rate of mutation by HIV, most conventional drugs are not effective due to the development of drug resistance. To reduce the development of multidrug resistance, therapy involving different classes of antiretrovirals is necessary [5]. However, this multidrug therapy can pose as a burden for patients especially when it must be taken daily. As one example, pre-exposure prophylaxis (PrEP) consisting of tenofovir and emtricitabine, both reverse transcriptase inhibitors and marketed as Truvada ${ }^{\circledR}$, demonstrated high efficacy against HIV-1 [6]. Interestingly, a study has reported that low patient compliance to Truvada may result in the development of antiviral drug resistance [7, 8]. Hence, the necessity to develop an easy and effective therapy against HIV that does not require daily drug administration is required. A great strategy is to develop microbicides (self-administrated topical PrEP) that do not require much effort from the user [9]. An ideal microbicide would be one that is long-acting and is capable of delivering high dose of drug to the target site demonstrating therapeutic efficacy and low toxicity. A common challenge with microbicide development as 
observed in clinical trials is low patient adherence [10]. In addition, some microbicides have also elicited inflammation within the FGT resulting in increased HIV infection rates [11-13]. Different microbicides have been developed in the past several decades including vaginal gels, creams, suppositories, bio-adhesives, and intravaginal ring [9, 14]. Intravaginal rings (IVRs) are an excellent alternative that can provide controlled and sustained release of an active ingredient within the FGT for an extended period [15]. IVRs have high acceptability amongst users and can be designed to deliver different active ingredients using the same ring [16, 17]. Furthermore, in a recent clinical trial, it was reported that placebo IVRs did not significantly induce an inflammatory response within the FGT of women suggesting that IVRs are safe for long-term use, e.g., 28 days [18]. In this study, we developed a dual-combination IVR system designed to prevent HIV infection by incorporating two distinct approaches. The first strategy will be to induce an immune quiescent state using hydroxychloroquine (HCQ) to reduce the number of HIV target cells within the FGT. Secondly, our IVR system will utilize gene therapy to knockdown the expression of CCR5 using small interfering RNA (siRNA) to reduce HIV binding to target cells.

It has been shown that high $\mathrm{CD} 4^{+} \mathrm{T}$ cell immune activation strongly correlates with HIV infection [19]. $\mathrm{CD} 4{ }^{+} \mathrm{CCR} 5^{+}$immune cells are the primary target cells for HIV. While activated, there will be an increase expression of cell surface markers such as HLA-DR, CD69, and CD38 resulting in an increase in the susceptibility for HIV infection [20]. Studies have shown that HIV-exposed seronegative women exhibit a unique immune phenotype called immune quiescence, whereby they exhibit a lower baseline of $\mathrm{T}$ cell immune activation when compared to people that are at a greater risk of contracting HIV [20, 21]. HCQ, a widely available FDA-approved immunomodulatory drug used for the treatment of malaria, systemic lupus erythematosus, and rheumatoid arthritis, has been shown to reduce HIV viral loads and induce $\mathrm{T}$ cell immune quiescence [22-24]. By using an IVR to deliver HCQ in a sustained and controlled manner at the site of infection e.g. FGT, it will greatly reduce viral infection during sexual intercourse. The immunomodulatory properties of HCQ are result of its ability to increase the $\mathrm{pH}$ of lysosomes within $\mathrm{T}$ cells, interfering with the association of the invariant chain of the major histocompatibility complex class II molecule leading to their reduced ability to process antigens $[25,26]$.

The second strategy will be to use siRNA directed against the CCR5 receptor expressed at the surface of T cells. HIV will bind to CD4 and CCR5 receptors at the surface of T cells to become internalized. Studies have shown that knocking down the CCR5 gene will prevent HIV-1 infection. For example, the first patient to be completely "cured" from HIV received a bone marrow transplant from a donor who had a rare stem cell mutation that prevented the expression of CCR5 on T cells. Three months after the transplant, the patient was completely cured of HIV [27]. Recently, a second case of another patient following the same treatment using CCR5 knockout stem cell transplant received from a donor was also cured of HIV [28]. Since it will be challenging to find sufficient donors for all HIV patients, using gene therapy to knockdown the CCR5 expression is a promising approach. In our study, we plan to deliver siRNA to target the CCR5 gene as a strategy for reducing HIV infection [29, 30]. siRNA being negatively charged cannot cross the cell membrane, and as a result, requires a carrier system such as solid lipid nanoparticles (SLN) to deliver siRNA into T cells. SLNs were used due to its demonstrated biocompatibility and simplicity in terms of customization. For active targeted delivery to immune cells, SLNs were functionalized with anti-CD4 antibody. The attached CD4 antibody will facilitate binding of SLNs to the CD4 receptor on the surface of $\mathrm{T}$ cells resulting in improved internalization.

Our study aims to develop and characterize a segmented combination IVR delivery system consisting of one-half of the IVR loaded with HCQ and the second-half of the IVR to be coated with a $\mathrm{pH}$-responsive film loaded with siRNAencapsulated SLNs. It is expected that at normal vaginal $\mathrm{pH}$ (3.5-4.3), there will be no release of siRNA-loaded nanoparticles. During heterosexual intercourse, the vaginal $\mathrm{pH}$ becomes elevated $(>6.2)$ due to the presence of seminal fluid [31]. As a result, it is expected that at $\mathrm{pH}>6.2$, the IVR will provide rapid release of siRNA-nanoparticles, while HCQ will be released continuously over time at both acidic and neutral $\mathrm{pH}$ to prevent immune activation of $\mathrm{T}$ cells. This novel dual combination microbicide has the potential to improve patient compliance and reduce HIV infection.

\section{Materials and methods}

\section{Materials}

Hydrophilic thermoplastic polyurethane (PU) (Tecophilic ${ }^{\mathrm{TM}}$ HP-60D-35) was purchased from Lubrizol Advanced Materials (Cleveland, OH, USA). Eudragit L100 (methacrylic acid-methyl acrylate copolymer; anionic $\mathrm{pH}$-sensitive polymer) was kindly donated by Evonik Industries (Essen, Germany). Hydroxypropyl methylcellulose (HPMC) K100M was donated by Dow Chemical Company (New Milford, CT, USA). Polyethylene glycol 400, NF (PEG-8) was acquired from Medisca (Saint-Laurent, QC, Canada). HCQ was purchased from Thermo Fisher Scientific (Burlington, ON, Canada). CellTiter 96® AQueous One Solution Cell Proliferation Assay (MTS) was purchased from Promega (Madison, USA). Glyceryl monostearate (molecular weight 358.56) 
was purchased from Sigma-Aldrich (Ontario, Canada). L- $\alpha$-phosphatidylcholine (Soy-95\%) (molecular weight $770.123 \mathrm{~g} / \mathrm{mol}$ ) was purchased from Avanti Polar Lipids (AL, USA). Polyvinyl alcohol (PVA; $31-50 \mathrm{kDa}$ ) and polyethyleneimine (PEI; branched, MW $25 \mathrm{~K}$ ) were obtained from Sigma-Aldrich (Ontario, Canada). Tris-EDTA was purchased from ThermoFisher Scientific (Ontario, Canada). 2-(N-morpholino) ethanesulfonic acid (MES) was purchased from Sigma-Aldrich (Ontario, Canada). 1-Ethyl3-(3-dimethylaminopropyl) carbodiimide (EDC; $200 \mathrm{mg} /$ $\mathrm{mL}$ ) N-hydroxysuccinimide (NHS; $275 \mathrm{mg} / \mathrm{mL}$ ) were purchased from G-Biosciences (Missouri, USA). Anti-Human CCR5 siRNA (sense: 5'-GUUCAGAAACUACCUCUU AdTdT-3', antisense: 3'-dTdTCAAGUVUUUGAUGGA GAAU-5') was purchased from Dharmacon (ON, Canada). Human CCR5 primers (Forward: 5'-TTCATCATCCTCCTG ACAATCG-3'; Reverse: 5'-GCCACCACCCAAGTGATC AC- $3^{\prime}$ ) and human GAPDH primer (Forward: 5'-AAGAAG GTGGTGAAGCAGGCG-3'; Reverse: 5'-AGACAACCT GGTCCTCAGTGTAGC-3') were purchased from Thermo Fisher (ON, Canada). E.Z.N.A. ${ }^{\circledR}$ RNA isolation kit was purchased from Sigma Aldrich (ON, Canada). PerfeCTa SYBR ${ }^{\circledR}$ Green SuperMix and qScript ${ }^{\mathrm{TM}}$ cDNA were purchased from Quanta (ON, Canada). Anti-CD4 antibody was purchased from Abcam (ON, Canada).

\section{Method}

\section{IVR fabrication}

"Reservoir-type" and "matrix-type" IVR segments were fabricated from medical grade PU (HP-60-D-35) pellets using hot-melt injection molding (Medium Machinery, LLC, Woodbridge, VA, USA). Briefly, the pellets were dried overnight at $80^{\circ} \mathrm{C}$ and loaded into a hot-melt injection molding. The PU was then melted inside the injection molder and injected into a custom-fabricated, pre-heated aluminum mold for the reservoir-type or matrix-type segment. The mold produced IVR segments with a 25 -mm outer diameter and 5-mm cross-sectional diameter for the matrix type IVR. The reservoir type IVR had a wall thickness of $0.75 \mathrm{~mm}$ (Fig. 1a), 25-mm outer diameter, and 5-mm crosssectional diameter. The reservoir-type segment containing HCQ in the lumen was joined to the matrix segment using a butt-welding kit.

\section{HCQ loading in reservoir-type IVR}

HCQ was mixed with HPMC K100M to create a semisolid as described previously [32]. Briefly, $160 \mathrm{mg}$ of HCQ was added to $1.28 \mathrm{~mL}$ of distilled water and mixed using the two-syringe method. About $160 \mathrm{mg}$ of HPMC K100M was added to the HCQ solution and mixed using the two-syringe method. The semisolid was passed through the syringes 80 times to ensure homogeneity. The mixture was loaded into a reservoir-type IVR segment with both ends sealed with resin caps pre-made using Smooth-Cast 300.

\section{Nanoparticle fabrication}

SLNs encapsulated with siRNA (siRNA-NP) were prepared using a double-emulsion solvent evaporation technique as previously described with slight modifications [33]. We added $50 \mu \mathrm{L}$ of $0.372 \mathrm{mg} / \mathrm{mL}$ PEI to a solution containing $45 \mu \mathrm{L}$ of Tris-EDTA buffer and $5 \mu \mathrm{L}$ of $25 \mu \mathrm{g}$ siRNA. The mixture was incubated at room temperature for $15 \mathrm{~min}$ and mixed periodically. This aqueous solution was added slowly to $1.4-\mathrm{mL}$ solution of glyceryl monostearate and L- $\alpha$-phosphatidylcholine dissolved in acetone and ethanol and sonicated for $30 \mathrm{~s}$ on ice using a probe sonicator. The double emulsion was formed by adding this mixture to $8 \mathrm{~mL}$ of $2 \%(\mathrm{w} / \mathrm{v})$ PVA solution. The organic solvents

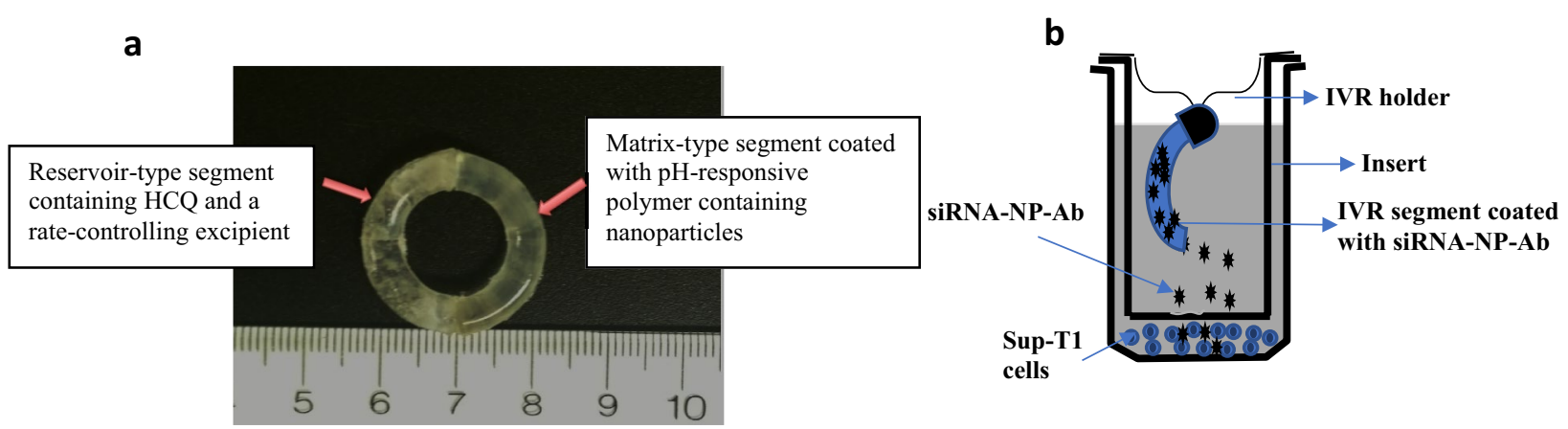

Fig. 1 a The picture depicts a segmented intravaginal ring (IVR) formed by combining a reservoir-type segment with a matrixtype segment. The size of the IVR $(25 \mathrm{~mm} \times 5 \mathrm{~mm})$ is designed for implantation into the female genital tract of non-human primates.
IVR segments were fabricated using hot-melt injection molding of HP-60-D-35 polyurethane pellets and joined by butt-welding. b Schematic representation of the IVR segment in a cell culture insert incubated with Sup-T1 cells in a 24-well plate 
were then evaporated, and the siRNA-NPs were washed, and the encapsulation efficiency was determined. Anti-CD4 antibody was conjugated to the siRNA-NP by activating the carboxyl group on the nanoparticle's surface by the addition of EDC and NHS at pH 6 for 60 min. The antibodyconjugated nanoparticles (siRNA-NP-Ab) were washed with distilled water, lyophilized, and stored at $-20{ }^{\circ} \mathrm{C}$ until further analysis. Nanoparticle size and net surface charge were determined by light scattering using Zetasizer (Malvern).

\section{pH-responsive coating preparation}

An optimized film formulation is necessary to achieve a uniform coating on the surface of the IVR. The coating should be able to stick to the IVR matrix when dried and not crumble or peel off when the IVR is compressed. For these reasons, we first evaluated the film forming capacity of Eudragit L100 and optimized the formulation that will work best for our IVR segments. Briefly, different percentages of Eudragit were dissolved in various organic solvents and evaluated for its film forming properties. The solvents include isopropanol, dichloromethane, methanol, dichloromethane:ethanol $(50: 50 \mathrm{v} / \mathrm{v})$, and methanol:water $(50: 50 \mathrm{v} / \mathrm{v})$. The mixture of organic solvent and Eudragit L100 was stirred at room temperature for at least $3 \mathrm{~h}$. After the complete dissolution of the polymer, PEG400 was added at different ratios (Table 2) and stirred for another $10 \mathrm{~min}$. In order to choose the best film formulation for the IVR coating, we performed a disintegration study to determine the rate of film disintegration. Briefly, 15 mg of Eudragit L100 films containing PEG were incubated in PBS buffer (pH 7.2) for 20 min. Afterwards, the remaining film was removed, dried in an oven at $37^{\circ} \mathrm{C}$, and weighed. For the complete disintegration time, we monitored the film until there was complete dissolution with no visible particles in the buffer. Next, after deciding on the formulation that gave the best adherence and the fastest disintegration time, siRNA-NP-Ab was added to the formulation (3\% Eudragit L100 plus $0.2 \mathrm{~mL}$ PEG 400), mixed and sonicated for 30 min without heat to obtain an aqueous dispersion and to remove air bubbles. A matrix IVR segment was coated with the mixture and dried at $40{ }^{\circ} \mathrm{C}$ for $15 \mathrm{~min}$.

\section{In vitro release studies from reservoir-type and matrix-type IVR segments}

Release studies were performed using reservoir-type IVR segments $(19.6 \pm 0.7 \mathrm{~mm})$ containing HCQ and K100M in the lumen as previously described [32] in vaginal fluid simulant (VFS; $\mathrm{pH} 4$ 4) following the recipe proposed by Owen et al. [34]. Briefly, IVR segments $(19.6 \pm 0.7 \mathrm{~mm})$ were placed in $5 \mathrm{~mL}$ of VFS at $100 \mathrm{rpm}$ speed and $37^{\circ} \mathrm{C}$. The amount of drug released was quantified using a reversephase HPLC method. Isocratic conditions were used with a Waters Nopak@ C18 column $(4 \mu \mathrm{m}, 3.9 \times 150 \mathrm{~mm})$ on Shimadzu LC-2010A HPLC system. The mobile phase consisted of 58-mM sodium phosphate dibasic buffer containing $15 \mathrm{mM}$ of heptanesulfonic acid, acetonitrile, and methanol at a volume ratio of 74:22:4, and the $\mathrm{pH}$ was adjusted to 3.1 with ortho-phosphoric acid. The flow rate was set at $1 \mathrm{~mL} / \mathrm{min}$, and the wavelength of the detector was set at $343 \mathrm{~nm}$. The column was kept at room temperature, and the HCQ retention time was approximately $8.4 \mathrm{~min}$. We aim to achieve a targeted HCQ release of at least $4.3 \mu \mathrm{g} / \mathrm{mL}$ which is the minimum concentration required to induce $\mathrm{T}$ cell immune quiescence [35].

Separately, the pH-responsive coated matrix-type IVR segments were placed in two different release buffers. The first release buffer was VFS ( $\mathrm{pH} 4.2$ ), and the second buffer was a seminal fluid simulant (SFS; pH 8.2) prepared using a modified recipe of Rastogi et al. [36]. SLN containing coumarin 6 (C6) was prepared to help track NP release from the IVR segments. Briefly, a set of segments coated with Eudragit L100 containing C6 -SLN were placed in $4 \mathrm{~mL}$ of VFS. The volume of ejaculated seminal fluid is between 0.1 and $11 \mathrm{~mL}$ [37, 38]. Ejaculation volume $<1 \mathrm{~mL}$ is considered hypospermia, and more than $6 \mathrm{~mL}$ is considered hyperspermia. In this study, we decided to evaluate the lowest normal ejaculation volume capable of changing the vaginal tract $\mathrm{pH}$. Accordingly, another set of IVR segments were placed in $4 \mathrm{~mL}$ of VFS $+1 \mathrm{~mL}$ of SFS to simulate the presence of seminal fluid during sexual intercourse and placed inside a rotary shaker at $37^{\circ} \mathrm{C}$ and set at $100 \mathrm{rpm}$. The data was analyzed using a fluorescent microplate reader (SpectraMax M5).

\section{In vitro CCR5 gene knockdown study}

In order to evaluate the efficacy of our SLN to deliver siRNA inside the cells and to know the minimum amount of siRNA needed to induce gene knockdown, we treated Sup-T1 cells in 96-well plate with only different concentrations of siRNA-NP-Ab. Briefly, SupT-1 cells were cultured in RPMI medium supplemented with $10 \%$ fetal bovine serum and $1 \%$ penicillin-streptomycin incubated at $37{ }^{\circ} \mathrm{C}$ with $5 \% \mathrm{CO}_{2}$. The cells were seeded in 96-well plate at a density of $2 \times 10^{4}$ cells/well. Each well was treated with $1.4 \mathrm{mg}, 0.7 \mathrm{mg}$, or $0.35 \mathrm{mg}$ of siRNA-NP-Ab. The cells were incubated for $48 \mathrm{~h}$ at $37^{\circ} \mathrm{C}$ with $5 \% \mathrm{CO}_{2}$. After incubation, the cells were washed with PBS and processed for mRNA extraction using the E.Z.N.A.® Total RNA Kit I. cDNA was transcribed using qScript ${ }^{\mathrm{TM}}$ cDNA SuperMix in a thermal cycler (Bio-Rad C1000 ${ }^{\mathrm{TM}}$ Thermal Cycler). RT-PCR was performed using the PerfeCTa SYBR Green SuperMix with GAPDH as an endogenous control.

For the next study, Sup-T1 cells were seeded in a 24 -well plate at a density of $0.8 \times 10^{5}$ cells per well. An 
insert was placed into each well, and an IVR segment coated with a pH-responsive polymer containing siRNA$\mathrm{NP}-\mathrm{Ab}$ (sterilized using ultraviolet light for $1 \mathrm{~h}$ ) was placed into the insert. The IVR segments were suspended above the insert using a custom designed holder made out of stainless-steel wire (Fig. 1b). Negative control had an insert containing an IVR segment coated with blank NPs and another well with nothing but cells. The plate was placed on a shaker inside an incubator set at $2 \mathrm{rpm}$ to allow dissolution of the coating for $48 \mathrm{~h}$ at $37^{\circ} \mathrm{C}$ with $5 \% \mathrm{CO}_{2}$. After incubation, we proceeded to the mRNA extraction and gene analysis as described above.

\section{In vitro cytotoxicity studies of IVR containing nanoparticles}

In vitro cytotoxicity was evaluated using the CellTiter $96{ }^{\circledR}$ Aqueous One Solution Cell Proliferation assay. Briefly, VK2/E6E7 vaginal epithelial cells were cultured in K-SFM containing $0.1 \mathrm{ng} / \mathrm{mL}$ recombinant human epidermal growth factor, $44.1 \mathrm{mg} / \mathrm{L}$ calcium, $0.05 \mathrm{mg} / \mathrm{mL}$ bovine pituitary extract, and $1 \%$ penicillin-streptomycin. The cells were incubated at $37{ }^{\circ} \mathrm{C}$ with $5 \% \mathrm{CO}_{2}$. Separately, this medium was used to incubate a matrix IVR segment coated with a pH-responsive polymer. The segment in the medium was incubated at $37^{\circ} \mathrm{C}$ for $24 \mathrm{~h}$ at $100 \mathrm{rpm}$ in an orbital shaker. After almost reaching confluency, the cells were seeded onto 96-well plates at a density of $2.5 \times 10^{5}$ cells per well. The cells were then incubated for another $24 \mathrm{~h}$, and the medium in each well was replaced with the elution medium collected previously. $1 \mathrm{M}$ acrylamide was used as positive control and plain medium was used as negative control. The cells were incubated back for another $24 \mathrm{~h}$ followed by the addition of $20 \mu \mathrm{L}$ of CellTiter $96 \AA$ Aqueous One Solution Cell Proliferation assay reagent and incubated for another $2 \mathrm{~h}$. The optical density of the wells was read using a microplate reader (SpectraMax M5) at $490 \mathrm{~nm}$, and data were normalized to the negative control value. Previously, we have shown that HCQ-loaded reservoir segments were non-cytotoxic [32].

\section{Results}

\section{IVR fabrication}

A photo of the matrix-type and reservoir-type IVR joined together are shown in Fig. 1a. A complete macaque-size IVR has a diameter of $25 \mathrm{~mm}$, and a cross-sectional diameter of $5 \mathrm{~mm}$. The reservoir-type IVR segment has a wall thickness of $\sim 0.7 \mathrm{~mm}$ and a length of $19.6 \pm 0.7 \mathrm{~mm}$. The lumen of the reservoir was filled with HCQ mixed with HPMC. The matrix IVR was coated with the modified $\mathrm{pH}$-responsive polymer containing siRNA-NP-Ab. Both segments were joined together via butt-welding by applying heat to partially melt both ends of the different segments.

\section{Nanoparticle fabrication}

The SLN size, net surface charge, and drug encapsulation efficiency were evaluated. The mean size of siRNA$\mathrm{NP}-\mathrm{Ab}$ was around $265.3 \pm 15.7 \mathrm{~nm}$ with a polydispersity index of around 0.2 . The siRNA encapsulation efficiency was $79.63 \pm 7.3 \%$, and the net surface charge was around $-26 \pm 3.4 \mathrm{mV}$. Drug-free SLN had an average size of $210.5 \pm 20.8 \mathrm{~nm}$ with a polydispersity index of 0.2 .

\section{pH-responsive coating preparation}

It is important to determine whether or not the selected solvent was capable of dissolving Eudragit L100. Table 1 lists the different solvents that were evaluated for their ability to dissolve Eudragit L100 and their film forming properties. Dichloromethane and dichloromethane:ethanol (50:50 v/v) were able to dissolve Eudragit L100 completely, but they also partially dissolved the PU HP-60D-35. Isopropanol was able to dissolve Eudragit L100 and did not have any effects on the PU. Table 2 summarizes the effects of varying amounts of Eudragit L100 and PEG 400 dissolved in isopropanol on film formation properties. The usage of low amounts of Eudragit L100 (3\%) with low amounts of PEG $400(0.1 \mathrm{~mL})$ resulted in the formation of fragile and easy to

Table 1 Eudragit L100 properties in different organic solvents and its impact on polyurethane

\begin{tabular}{lccccc}
\hline & \multicolumn{2}{c}{ Percentage of Eudragit L100 } & & $\begin{array}{l}\text { Film forming } \\
\text { properties }\end{array}$ & Effects on polyurethane \\
\cline { 2 - 5 } Solvents & $1 \%$ & $3 \%$ & $5 \%$ & & \\
\hline Methanol:Water $(50: 50 \mathrm{v} / \mathrm{v})$ & Insoluble & Insoluble & Insoluble & No & None \\
Methanol & Partially soluble & Insoluble & Insoluble & No & None \\
Dichloromethane & Soluble & Soluble & Soluble & Yes & Dissolved \\
Dichloromethane:Ethanol (50:50 v/v) & Soluble & Soluble & Soluble & Yes & Partially dissolved \\
Isopropanol & Soluble & Soluble & Soluble & Yes & None \\
\hline
\end{tabular}


Table 2 Impact of varying amounts of Eudragit L100 and PEG 400 dissolved in isopropanol on film formation

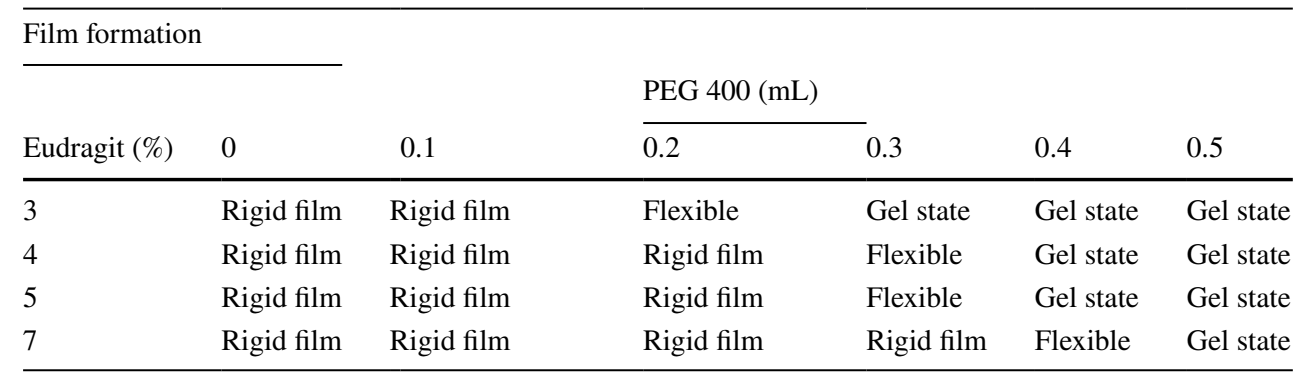

break films. Higher amounts of PEG $400(0.5 \mathrm{~mL})$ hindered the film forming capacity of Eudragit L100 resulting in gellike mixture. As a result, 3\% Eudragit L100 dissolved in isopropanol supplemented with $0.2 \mathrm{~mL}$ of PEG 400 was used for all downstream studies since it produced the most uniform film with the fastest disintegration time. We observed rapid disintegration within the first $20 \mathrm{~min}$ (42\%) followed by a reduced rate of disintegration for the next $2.5 \mathrm{~h}$. Complete film dissolution was achieved in $3 \mathrm{~h}$ (Table 3 ). Only the formulations capable of forming a uniform and flexible film were considered in Table 3 for the disintegration study. The use of higher amounts of Eudragit L100 (>3\%) resulted in films with longer disintegration times $(>5 \mathrm{~h})$.

\section{In vitro release}

Release studies were performed on reservoir-type IVR segments containing $\mathrm{HCQ} / \mathrm{HPMC}$ in VFS separately from the matrix-type IVR. We previously published a study evaluating the release of HCQ from HP-60D-35 IVR segments in sodium acetate buffer [15]. In this study, release was evaluated in VFS which more closely represents the physiological environment. HCQ released from the IVR segment was sustained over 25 days with a mean daily release of $31.17 \pm 3.06 \mu \mathrm{g} / \mathrm{mL}$ following a near-zero release kinetic profile $\left(R^{2}=0.998\right)$ (Fig. 2$)$. Over the period of 25 days, $19.81 \pm 1.3 \%$ of the total amount loaded was released. The matrix-type IVR segment coated with the $\mathrm{pH}$-responsive polymer containing C6-SLN was introduced in two different buffers for the release study. After $4 \mathrm{~h}$, the segment placed in VFS released $0.42 \pm 0.19 \mathrm{mg}$ of C6-SLN, while

Table 3 Eudragit L100 film disintegration time

\begin{tabular}{lll}
\hline Eudragit/PEG & $\begin{array}{l}\text { PBS pH } 4.0 \\
\text { Disintegration time }\end{array}$ & PBS pH 7.2 \\
\hline $3 \% / 0.2 \mathrm{~mL}$ & None & $<3 \mathrm{~h}$ \\
$4 \% / 0.3 \mathrm{~mL}$ & None & $>5 \mathrm{~h}$ \\
$5 \% / 0.3 \mathrm{~mL}$ & None & $>5 \mathrm{~h}$ \\
$7 \% / 0.4 \mathrm{~mL}$ & None & $>6 \mathrm{~h}$ \\
$7 \% / 0.5 \mathrm{~mL}$ & None & $>6 \mathrm{~h}$ \\
\hline
\end{tabular}

the IVR segment that was incubated in VFS supplemented with SFS buffer released $12 \times$ higher amounts of C6-SLN $(5.12 \pm 0.9 \mathrm{mg})$ (Fig. 3).

\section{Determination of the in vitro cytotoxicity of IVR containing SLNs}

The safety profile of the reservoir-type IVR segments containing HCQ/HPMC was previously evaluated and published [32]. As a result, we focused only on the second half of the IVR in this study. As shown in Fig. 4, no significant cytotoxicity was observed in VK2/E6E7 cells incubated with
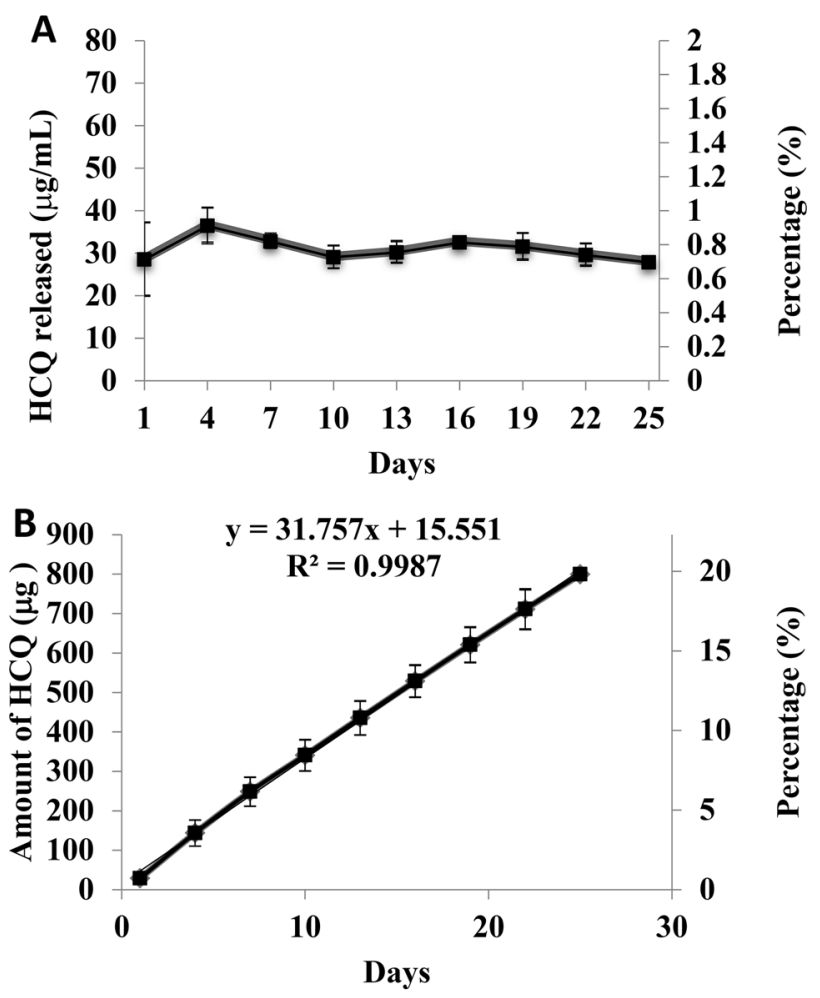

Fig. 2 a Daily release of HCQ from HCQ/HPMC-loaded (ratio 1:1 $\mathrm{wt} / \mathrm{wt}$ ) IVR segments for 25 days. Release studies were performed in $5 \mathrm{~mL}$ of VFS ( $\mathrm{pH} 4.2$ ) and shaken on an orbital shaker at $37{ }^{\circ} \mathrm{C}$, $100 \mathrm{rpm}$. Data represents mean \pm S.D.; $N=4$. b Cumulative release of HCQ from HCQ/HPMC-loaded (ratio 1:1 wt/wt) IVR segments for 25 days. Data represents mean \pm S.D.; $N=4$ 


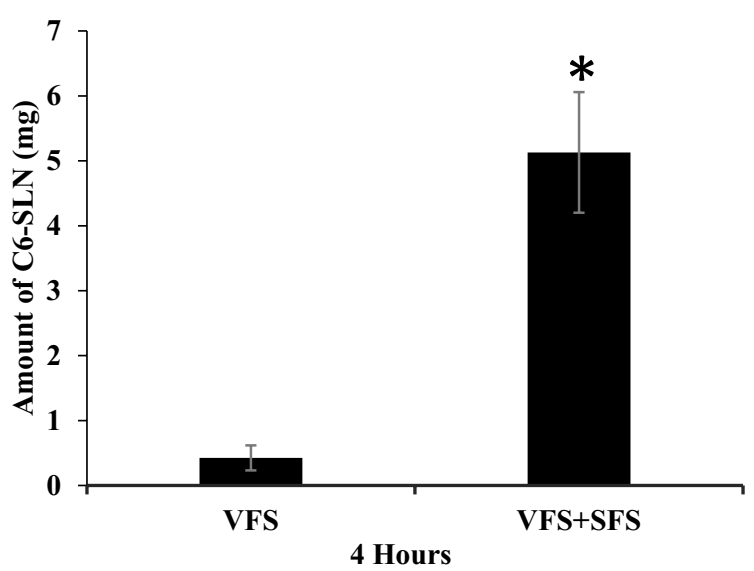

Fig. 3 Release study of C6-SLN in VFS only and in VFS plus SFS to simulate the presence of seminal fluid during sexual intercourse. Data represents the mean $\pm \mathrm{SD}(n=4)$. $* P<0.05$ versus VFS. C6 coumarin- 6 , VFS vaginal fluid simulant, SFS seminal fluid simulant

matrix-type IVR segments coated with the SLN-loaded $\mathrm{pH}$ responsive coating in comparison to the control.

\section{In vitro CCR5 downregulation study}

To evaluate the gene knockdown efficiency of the SLN containing siRNA, siRNA-NP-Ab were incubated directly with SupT-1 cells. Cells treated with 1.4 mg of siRNA-NP-Ab for $48 \mathrm{~h}$ (containing approximately $5 \mu \mathrm{g}$ of siRNA) were

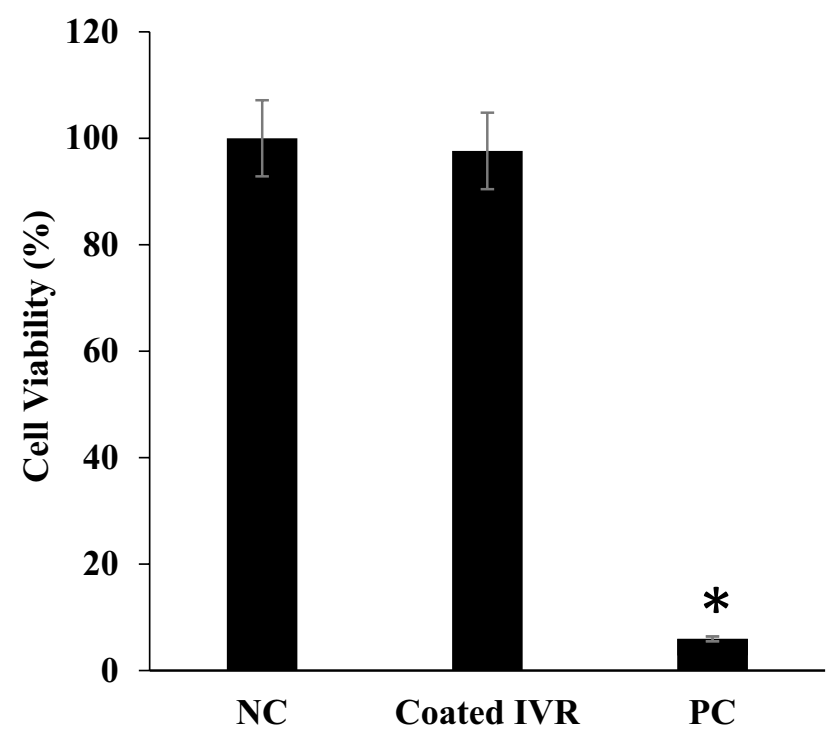

Fig. 4 Cytotoxicity evaluation of IVR segments coated with Eudragit L100 on VK2/E6E7 vaginal epithelial cells. The IVR segment was coated with $15 \mathrm{mg}$ of Eudragit L100 film. PC positive control (1 M acrylamide); NC negative control (cell media). Data represents mean \pm S.D.; $N=4$. ${ }^{*} P<0.05$ versus NC

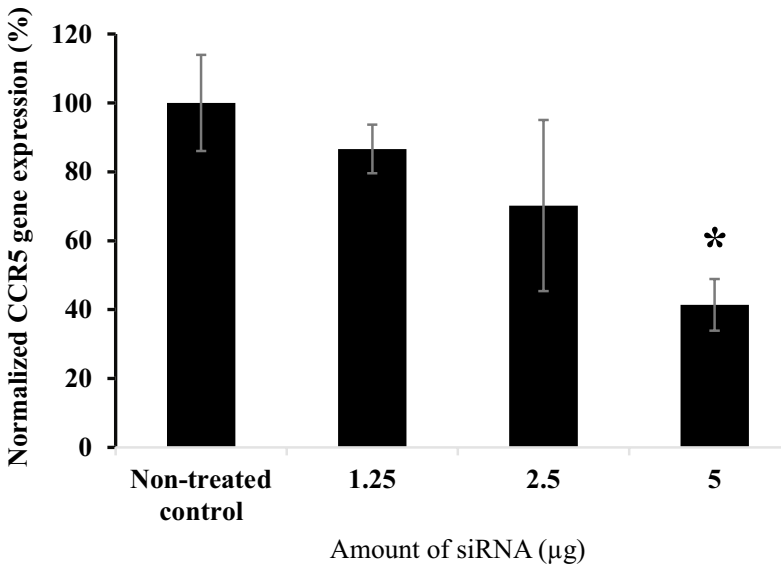

Fig. 5 Evaluation of CCR5 gene expression using real-time PCR. The $\mathrm{T}$ cell line (Sup-T1) was treated with various concentrations of siRNA-NP-Ab for $48 \mathrm{~h}$. Data represents mean \pm S.D.; $N=3$. $* P<0.05$ versus non-treated control

able to achieve close to $60 \%$ CCR5 gene knockdown in 96-well plate (Fig. 5). IVR segments coated with $7 \mathrm{mg}$ of siRNA-NP-Ab (containing around $2.84 \mu \mathrm{g}$ of siRNA per $\mathrm{mg}$ of SLN) were able to release enough SLNs to significantly reduce CCR 5 gene expression by $83 \pm 5.1 \%$ in comparison to controls after $48 \mathrm{~h}$ of incubation in Sup-T1 cells in a 24-well plate (Fig. 6).

\section{Discussion}

HIV continues to be a major global health concern particularly for women, who are disproportionally impacted due to biological and socio-cultural factors. Many of the

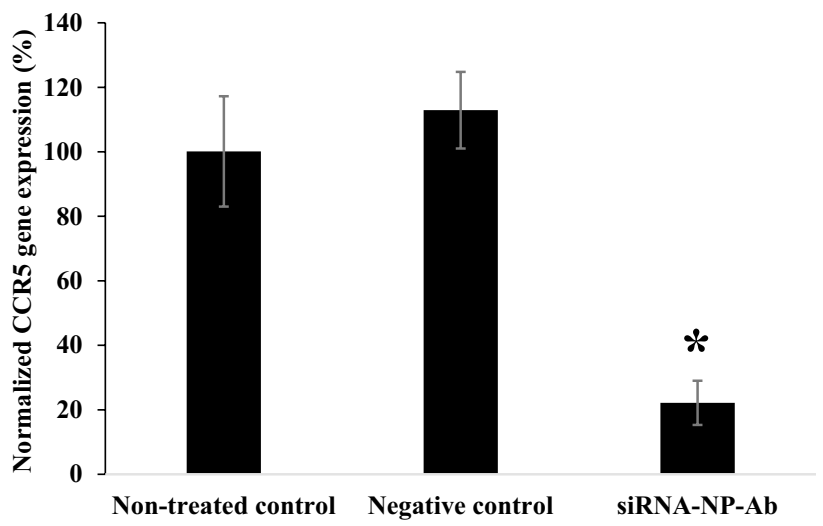

Fig. 6 CCR5 gene knockdown in Sup-T1 cells incubated with IVR segments coated with $\mathrm{pH}$-responsive Eudragit L100/PEG containing siRNA-NP-Ab $(\sim 19.09 \mu \mathrm{g}$ of anti-CCR5 siRNA). Blank: Sup-T1 cells alone; negative control: consists of the IVR segment coated with the $\mathrm{pH}$-responsive polymer but with drug-free SLNs. Data represents mean \pm S.D.; $N=3$. $* P<0.05$ versus negative control 
current therapies fail due to low patient compliance and the development of drug resistance [39]. An IVR system that can provide prolonged drug release and is easily administered without the assistance of a healthcare practitioner will increase patient adherence [40]. Furthermore, using two different strategies that prevent HIV access to its target cells will greatly reduce infectivity and the potential to develop drug resistance. Our system is designed to deliver HCQ continuously for over 3 weeks to induce a $\mathrm{T}$ cell immune quiescent state within the FGT as the first-line of defense. During heterosexual intercourse, the second half of the IVR will rapidly release anti-CCR5 siRNA-NP-Ab to reduce the expression of CCR5 as the second-line of defense. However, further evaluation of our IVR system is required to determine whether or not drug resistance will develop.

HIV-exposed seronegative sex workers exhibit a low baseline of immune activation within the FGT [21]. It is believed that this immune quiescent state plays an important role in protecting against HIV infection. We decided to induce $\mathrm{T}$ cell immune quiescence using the immunomodulatory drug HCQ. It has been shown that HIV-exposed seronegative people exhibit low baseline immune activation with reduced expression of HLA-DR, CD38, CD69, and CCR5 on T cells [20, 41, 42]. In our study, HCQ was able to cross the hydrophilic PU wall of the IVR segments while immersed in buffer. The PU HP-60D-35 has a water swellability of $35 \%$ of its mass. The influx of water inside the polymer will aid in the diffusion of HCQ. To further control the diffusion of HCQ, a rate-controlling excipient HPMC was used. The concentration needed to induce immune quiescence in vitro is $\sim 4.3 \mu \mathrm{g} / \mathrm{mL}[22,43]$. The IVR segment is capable of releasing at least 7 folds more than the required concentration to induce immune quiescence. We demonstrated in previous studies that HCQ released from HP-60D-35 was safe in a rabbit model, in the presence of vaginal (VK2/E6E7) and cervical (ECT-1/E6E7) epithelial cells, and in the presence of normal flora Lactobacillus jensenii and crispatus $[32,44]$. The concentration of HCQ released in this study is significantly lower than the concentration reported that can induce cytotoxicity in vaginal cells $(433.96 \mu \mathrm{g} / \mathrm{mL})$ and Lactobacillus jensenii and crispatus $(7 \mathrm{mg} / \mathrm{mL})$ [32].

The second half of the IVR segment was fabricated to release anti-CCR5 siRNA-NP-Ab at high $\mathrm{pH}$. The antiCCR5 siRNA was mixed with PEI prior to encapsulation into SLNs. We believe once inside the cells, the siRNA can escape endosomal degradation via the proton sponge effect imparted by the positively charged PEI [45]. PEI has been shown to aid in the condensation of siRNA improving its encapsulation efficiency and assisting in the proton sponge effect by rupturing endosomes due to osmotic swelling.

To avoid unnecessary gene knockdown when it is not required, well-timed release of SLN is important. Release of SLNs can be triggered during sexual intercourse by the presence of seminal fluid inside the FGT. This can be achieved by using Eudragit L100 that will react with the change in $\mathrm{pH}$ environment due to the presence of seminal fluid. Eudragit L100 made of poly(methacrylic acid-co-methacrylate) is protonated and uncharged at acidic $\mathrm{pH}$. At basic $\mathrm{pH}$, it will become deprotonated and the negative charges repel themselves causing the polymer to swell [46, 47]. The swelling of the polymer leads to its disintegration and the release of the SLNs. For the fabrication of the pH-responsive film, we evaluated different solvents capable of dissolving Eudragit L100 (Table 1). The aim of this experiment was to find the most suitable solvent capable of dissolving only Eudragit L100 but not the PU matrix that it is coated on. Isopropanol appeared to completely dissolve Eudragit L100 and not have any visible effects on the PU HP-60D-35. Disintegration time of the $\mathrm{pH}-$ responsive film is also important since the rate of SLN release needs to be rapid during sexual intercourse. Since HCQ is continuously released to maintain $\mathrm{T}$ cell immune quiescence, it is assumed that this will provide sufficient time for the SLNs to be released, enter $\mathrm{CD} 4^{+} \mathrm{T}$ cells and silence CCR5 gene expression to prevent infection. In a non-human primate study, the authors have shown that sufficient infection was established only after 4 days [48]. Studies have shown that cervicovaginal mucus within the FGT may hinder nanoparticles from reaching the underlying submucosa [49]. As a result, the SLNs we prepared were coated with PEG that will potentially enhance the mucus penetration ability of the particles as described by others [50]. Assuming there is no mechanical tearing of the vaginal epithelium during sexual intercourse, we expect our SLNs to enter the target cells and knockdown CCR5 gene expression in less than 4 days. For the SLN release studies, C6, a hydrophobic fluorescent dye was used to monitor the SLNs. As expected, in VFS alone, very low amounts of SLN were released. To simulate sexual intercourse, $1 \mathrm{~mL}$ of SFS was added to the VFS. In a study by Fox et al., the authors measured changes in vaginal $\mathrm{pH}$ during sexual intercourse using radio-telemetry and found that low volumes of semen $(1.5 \mathrm{~mL})$ were capable of raising vaginal $\mathrm{pH}$ from 3.5 to 5.5 within $15 \mathrm{~s}$ [51]. At higher volumes of semen ( 5 to $6 \mathrm{~mL})$, the vaginal $\mathrm{pH}$ can be raised from 4.3 to 7.2 in $8 \mathrm{~s}$ [51]. For our studies, we used $1 \mathrm{~mL}$ of SFS which was capable of raising the $\mathrm{pH}$ of VFS from 4.2 to 7.3. This volume was selected to mimic the lower range of ejaculated seminal fluid, which was sufficient in removing almost the entire $\mathrm{pH}$ responsive coating on the IVR segment. Human seminal fluid has a high buffering capacity and can easily change the vaginal tract $\mathrm{pH}$ from acidic to neutral and basic $[52,53]$.

In our studies, we determined that as low as $5 \mu \mathrm{g}$ of siRNA was capable of knocking down gene expression by around $50 \%$. This study also confirmed that there was sufficient uptake of SLN by Sup-T1 cells to significantly reduce CCR 5 mRNA expression. It took $48 \mathrm{~h}$ for the siRNA to be released from the SLNs to induce gene knockdown. However, further 
studies must be performed in vivo to evaluate how fast the SLNs will reach the submucosa and to determine its efficiency in preventing HIV infection [48]. For in vivo studies, it is possible that other surrounding cells, e.g., vaginal epithelial cells, may uptake the SLN, as a result, functionalizing the SLN with anti-CD4 antibody will improve targeted delivery to $\mathrm{CD} 4^{+} \mathrm{T}$ cells. Lastly, we determined that the coated IVR segments were non-cytotoxic to VK2/E6E7 vaginal epithelial cells. We have previously shown that PU HP-60D-35 is stable under accelerated stressed conditions of $40{ }^{\circ} \mathrm{C}$ and $75 \%$ relative humidity [15], but further studies are needed to confirm the stability of the $\mathrm{pH}$-responsive coating under the same conditions. Although room temperature may not affect the coating, it is unknown what impact countries with elevated climates and humidity may have.

\section{Conclusion}

To the best of our knowledge, this is the first study to combine the delivery of HCQ and gene therapy as a novel strategy for preventing HIV infection. We were able to deliver HCQ continuously for over 3 weeks and also rapidly deliver siRNA-NP-Ab only at elevated $\mathrm{pH}$ environments such as those simulating the presence of seminal fluid. We were able to achieve significant CCR5 gene knockdown in comparison to controls, and the IVR segment was non-cytotoxic towards vaginal epithelial cells. Overall, combining chemotherapy and gene therapy into a single IVR is a promising platform that should be further explored for its potential as a microbicide.

Acknowledgements The authors would like to thank Vincent Jimenez, Gabriel Luo, and Sidi Yang for their technical help.

Author contribution Yannick L. Traore, Yufei Chen, and Emmanuel Ho helped with the study conception and design. Material preparation, data collection, and analysis were performed by Yannick L. Traore and Fernanda Padilla. The manuscript was written by Yannick L. Traore and Emmanuel Ho.

Funding This study was funded in part by a Canadian Institutes of Health Research Project Grant (PJT166153) and a Natural Sciences and Engineering Research Council of Canada Discovery Grant (RGPIN20156-06008) awarded to Emmanuel A. Ho.

Availability of data and material All data generated or analyzed during this study are included in this published article.

\section{Declarations}

Conflict of interest The authors declare no competing interests.
Open Access This article is licensed under a Creative Commons Attribution 4.0 International License, which permits use, sharing, adaptation, distribution and reproduction in any medium or format, as long as you give appropriate credit to the original author(s) and the source, provide a link to the Creative Commons licence, and indicate if changes were made. The images or other third party material in this article are included in the article's Creative Commons licence, unless indicated otherwise in a credit line to the material. If material is not included in the article's Creative Commons licence and your intended use is not permitted by statutory regulation or exceeds the permitted use, you will need to obtain permission directly from the copyright holder. To view a copy of this licence, visit http://creativecommons.org/licenses/by/4.0/.

\section{References}

1. Fowler MG, Melnick SL, Mathieson BJ. Women and HIV. Epidemiology and global overview. Obstet Gynecol Clin N Am. 1997;24(4):705-729.

2. Ickovics JR, Rodin J. Women and AIDS in the United States: epidemiology, natural history, and mediating mechanisms. Health Psychol. 1992;11(1):1-16.

3. Unaids. Global HIV \& AIDS statistics - 2020 fact sheet. 2020.

4. García-Moreno $\mathrm{C}$, et al. Addressing violence against women: a call to action. The Lancet. 2015;385(9978):1685-95.

5. Dimitrov DT, et al. How much do we know about drug resistance due to PrEP use? Analysis of experts' opinion and its influence on the projected public health impact. 2016;11(7):e0158620.

6. Grant RM, et al. Preexposure chemoprophylaxis for HIV prevention in men who have sex with men. N Engl J Med. 2010;363(27):2587-99.

7. Tuller D. HIV prevention drug's slow uptake undercuts its early promise. Health Aff. 2018;37(2):178-80.

8. Knox DC, et al. Multidrug-resistant HIV-1 infection despite preexposure prophylaxis. N Engl J Med. 2017;376(5):501-2.

9. Traore YL, Chen Y, Ho EA. Current state of microbicide development. Clin Pharmacol Ther. 2018;104(6):1074-81.

10. Gengiah TN, et al. Adherence challenges with drugs for preexposure prophylaxis to prevent HIV infection. Int J Clin Pharm. 2014;36(1):70-85.

11. Van Damme L, et al. Effectiveness of COL-1492, a nonoxynol-9 vaginal gel, on HIV-1 transmission in female sex workers: A randomised controlled trial. Lancet. 2002;360(9338):971-7.

12. Poynten IM, et al. The safety of candidate vaginal microbicides since nonoxynol-9: a systematic review of published studies. AIDS. 2009;23(10).

13. Van Damme L, et al. Lack of effectiveness of cellulose sulfate gel for the prevention of vaginal HIV transmission. N Engl J Med. 2008;359(5):463-72.

14. D'Cruz OJ, Uckun FM. Vaginal microbicides and their delivery platforms. Expert Opin Drug Deliv. 2014;11(5):723-40.

15. Chen Y, et al. Development of polyether urethane intravaginal rings for the sustained delivery of hydroxychloroquine. Drug Des Dev Ther. 2014;8:1801-15.

16. Novák A, et al. The combined contraceptive vaginal ring, NuvaRing: an international study of user acceptability. Contraception, 2003;67(3):187-94.

17. Baum MM, et al. An intravaginal ring for the simultaneous delivery of multiple drugs. J Pharm Sci. 2012;101(8):2833-43.

18. Keller MJ, et al. Tenofovir disoproxil fumarate intravaginal ring for HIV pre-exposure prophylaxis in sexually active women: a 
phase 1, single-blind, randomised, controlled trial. The Lancet HIV. 2019;6(8):e498-508.

19. Klatt NR, et al. Immune activation and HIV persistence: implications for curative approaches to HIV infection. Immunol Rev. 2013;254(1):326-42.

20. Card CM, Ball TB, Fowke KR. Immune quiescence: a model of protection against HIV infection. Retrovirology. 2013;10:141.

21. McLaren PJ, et al. HIV-exposed seronegative commercial sex workers show a quiescent phenotype in the CD4+ T cell compartment and reduced expression of HIV-dependent host factors. J Infect Dis. 2010;202(Suppl 3):44.

22. Sperber K, et al. Hydroxychloroquine treatment of patients with human immunodeficiency virus type 1 . Clin Ther. 1995; 17(4):622-36.

23. Vatakis DN, Nixon CC, Zack JA. Quiescent T cells and HIV: an unresolved relationship. Immunol Res. 2010;48(1-3):110-21.

24. Lajoie $\mathbf{J}$, et al. Using safe, affordable and accessible non-steroidal anti-inflammatory drugs to reduce the number of HIV target cells in the blood and at the female genital tract. J Int AIDS Soc. 2018;21(7):e25150.

25. Lombard-Platlet $\mathrm{S}$, et al. Inhibition by chloroquine of the class II major histocompatibility complex-restricted presentation of endogenous antigens varies according to the cellular origin of the antigen-presenting cells, the nature of the T-cell epitope, and the responding T cell. Immunology. 1993;80(4):566-73.

26. Schmidt RLJ, et al. Chloroquine inhibits human CD4+ T-cell activation by AP-1 signaling modulation. Scientific Reports. 2017;7:42191.

27. Brown TR. Timothy Ray Brown's continuing activism toward curing HIV. AIDS Res Hum Retroviruses. 2018;34(1):9-11.

28. Gupta RK, et al. Evidence for HIV-1 cure after CCR5 $\Delta 32 / \Delta 32$ allogeneic haemopoietic stem-cell transplantation 30 months post analytical treatment interruption: a case report. The Lancet HIV. 2020;7(5).

29. Viruses LL. CCR5: from natural resistance to a new anti-HIV strategy. Viruses. 2010;2(2):574-600.

30. Kim SS, et al. RNAi-mediated CCR5 silencing by LFA-1-targeted nanoparticles prevents HIV infection in BLT mice. Mol Ther. 2010;18(2):370-6.

31. Harraway C, Berger NG, Dubin NH. Semen $\mathrm{pH}$ in patients with normal versus abnormal sperm characteristics. Am J Obstet Gynecol. 2000;182(5):1045-7.

32. Traore YL, Chen Y, Bernier AM. Impact of hydroxychloroquineloaded polyurethane intravaginal rings on Lactobacilli. Antimicrob Agents Chemother. 2015;59(12):7680-6.

33. Kim S, et al. Design and development of $\mathrm{pH}$-responsive polyurethane membranes for intravaginal release of nanomedicines. Acta Biomater. 2018;82:12-23.

34. Owen DH, Katz DF. A vaginal fluid simulant. Contraception. 1999;59(2):91-5.

35. Goldman FD, et al. Hydroxychloroquine inhibits calcium signals in T cells: a new mechanism to explain its immunomodulatory properties. Blood. 2000;95(11):3460-6.
36. Rastogi $R$, et al. Engineering and characterization of simplified vaginal and seminal fluid simulants. Contraception. 2016;93(4):337-46.

37. Rehan N, Sobrero AJ, Fertig JW. The semen of fertile men: statistical analysis of 1300 men. Fertil Steril. 1975;26(6):492-502.

38. Cooper TG, et al. World Health Organization reference values for human semen characteristics. Hum Reprod Update. 2010;16(3):231-45.

39. Kiertiburanakul S, Research SS. Emerging of HIV drug resistance: epidemiology, diagnosis, treatment and prevention. Curr HIV Res. 2009;7(3):273-8.

40. Thurman A, et al. Intravaginal rings as delivery systems for microbicides and multipurpose prevention technologies. Int J Women's Health. 2013;5:695-708.

41. Camara M, et al. Low-level CD4+ T cell activation in HIVexposed seronegative subjects: influence of gender and condom use. J Infect Dis. 2010 Mar 15;201(6):835-42.

42. Bégaud E, et al. Reduced CD4 T cell activation and in vitro susceptibility to HIV-1 infection in exposed uninfected Central Africans. Retrovirology. 2006 Jun 22;3:35.

43. Goldman FD, et al. Hydroxychloroquine inhibits calcium signals in T cells: a new mechanism to explain its immunomodulatory properties. Blood. 2000;95(11):3460-6.

44. Chen Y, et al. Implant delivering hydroxychloroquine attenuates vaginal $\mathrm{T}$ lymphocyte activation and inflammation. J Control Release. 2018;277:102-13.

45. Wojnilowicz M, et al. Super-resolution imaging of proton spongetriggered rupture of endosomes and cytosolic release of small interfering RNA. ACS Nano. 2019;13(1):187-202.

46. Kocak G, Tuncer C, Bütün V. pH-responsive polymers. Polym Chem. 2016;8(1):144-76.

47. Thakral S, Thakral NK, Majumdar DK. Eudragit: a technology evaluation. Expert Opin Drug Deliv. 2013 Jan;10(1):131-49.

48. Miller CJ, et al. Propagation and dissemination of infection after vaginal transmission of simian immunodeficiency virus. J Virol. 2005;79(14):9217-27.

49. Lai SK, Wang YY, Hanes J. Mucus-penetrating nanoparticles for drug and gene delivery to mucosal tissues. Adv Drug Deliv Rev. 2009;61(2):158-71.

50. Suk JS, et al. PEGylation as a strategy for improving nanoparticlebased drug and gene delivery. Adv Drug Deliv Rev. 2016;99(Pt A):28-51.

51. Fox CA, Meldrum SJ, Watson BW. Continuous measurement by radio-telemetry of vaginal $\mathrm{pH}$ during human coitus. Reproduction. 1973;33(1):69-75.

52. Bouvet JP, Grésenguet G, Bélec L. Vaginal pH neutralization by semen as a cofactor of HIV transmission. Clin Microbiol Infect. $1997 \mathrm{Feb} ; 3(1): 19-23$

53. Wolters-Everhardt E, et al. Buffering capacity of human semen. Fertil Steril. 1986;46(1):114-9.

Publisher's Note Springer Nature remains neutral with regard to jurisdictional claims in published maps and institutional affiliations. 